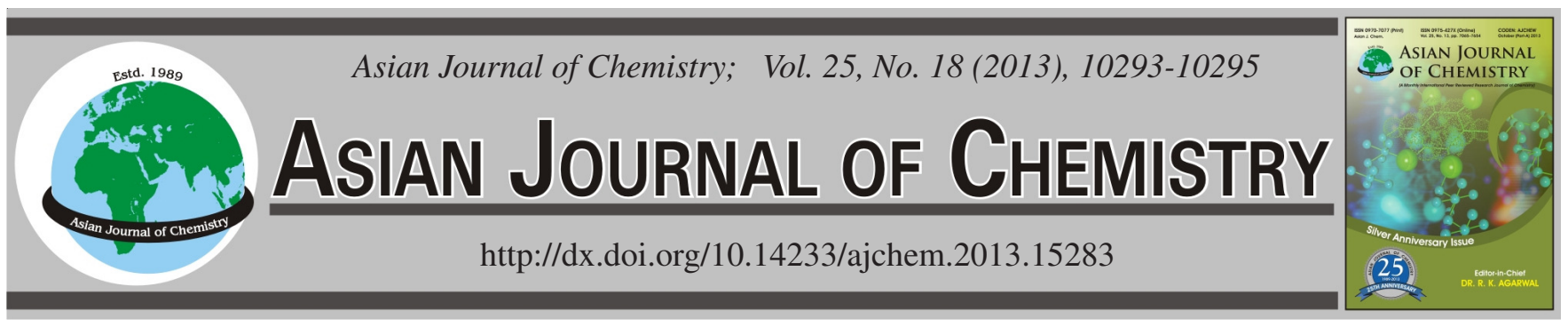

\title{
Acute and Chronic Toxic Effects of Chloramphenicol, Erythromycin and Tetracycline on the Early Life Stage of Amphibian (Xenopus tropicalis)
}

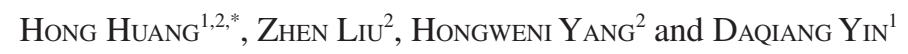

${ }^{1}$ Key Laboratory of Yangtze River Water Environment, Ministry of Education, College of Environmental Science and Engineering, Tongji University, Shanghai, P.R. China

${ }^{2}$ College of Marine Science, Shanghai Ocean University, Shanghai, P.R. China

*Corresponding author: Tel: +86 21 61900332; E-mail: hhuang@ shou.edu.cn

(Received: 6 February 2013;

Accepted: 14 November 2013)

AJC-14387

An acute and a chronic test with the tadpole embryos at stage 46 of amphibian (Xenopus tropicalis) were conducted to determine the toxic |
effects of chloramphenicol, erythromycin and tetracycline. In the acute test, both the percentage of survival and the whole body length
were slightly decreased; the percentage of teratogenesis was increased compared with the control. The chloramphenicol and tetracycline
had a higher percentage of teratogenesis than erythromycin. In the chronic test, the cumulative mortality was $11.7,21.1$ and $30.8 \%$ in the
treatment group with $1 \mathrm{mg} / \mathrm{L}$ of chloramphenicol, erythromycin and tetracycline, respectively. Three antibiotics can inhibit the growth of |
the embryos of $X$. tropicalis. The whole body length and the biomass were decreased and the developmental stages were also delayed. The |
chronic test with larvaes of $X$ tropicalis was much more sensitive than the acute test. These findings may help to understand the potential
biological effects of antibiotics on aquatics organisms.
Key Words: Chloramphenicol, Erythromycin, Tetracycline, Xenopus tropicalis, Teratogenesis.

\section{INTRODUCTION}

Antibiotics were used for treating diseases of humans and animals, also as growth promoters in agriculture or aquaculture to improve feeds' nutritional efficiency ${ }^{1}$. Wise ${ }^{2}$ had estimated total consumption in antibiotic market in the world ranging 100000-200000 tons. In China, about 23,000 ton of antibiotics were produced each year and $40 \%$ was used in agriculture ${ }^{3}$.

Antibacterial agents often have a low biodegradability, thus poses a potential for bioaccumulation and persistence in the environment ${ }^{4}$. However, few experimental data are available on the ecotoxicity of antibiotics. In recent years, more attention has been drawn towards the potential adverse effects of antibiotics. Handerson et al. ${ }^{5}$ had predicted $1 / 5$ of the antibiotics were very toxic to algae, $16 \%$ were extremely toxic $\left(\mathrm{EC}_{50}<0.1 \mathrm{mg} / \mathrm{L}\right)$ and $44 \%$ were very toxic $\left(\mathrm{EC}_{50}<1 \mathrm{mg} / \mathrm{L}\right)$ to Daphnis. Almost $1 / 3$ of all of antibiotics were very toxic to fish and more than half are toxic $\left(\mathrm{EC}_{50}<10 \mathrm{mg} / \mathrm{L}\right)$ to fish ${ }^{5}$. Lai et al. ${ }^{6}$ investigated chloramphenicol, florfenicol and thiamphenicol and found that these chemicals could inhibit growth of three microalgae at $\mathrm{mg} / \mathrm{L}$ level. Sulfonamides had negative effects on the reproduction of Daphnia magna in the range $131-270 \mathrm{mg} / \mathrm{L}^{7}$. For the macrolide antibiotic roxithromycin, Oryzias latipes exhibited $96 \mathrm{~h} \mathrm{LC}_{50}$ at $288.3 \mathrm{mg} / \mathrm{L}^{8}$.

\section{EXPERIMENTAL}

Chloramphenicol (CAP), erythromycin (ETM) and tetracycline (TC) purchased from ARCOS were of HPLC grade. 3-amino-benzoic acid ethyl ester (MS-222) and dimethyl sulphoxide (DMSO) were purchased from Sigma-Aldrich. L-cysteine was obtained from Sinopharm Chemical Reagent Co., Ltd. (Shanghai, China). All other chemicals used in this study were analytical grade.

Exposure experiments: Husbandry of $X$. tropicalis was conducted according to the description in the literature of $\mathrm{Yu}^{9}$. Exposure experiments were conducted according to the frog embryo teratogenesis assay-Xenopus (FETAX) with some modifications ${ }^{10}$. About $12 \mathrm{~h}$ after the second injection of hCG, adults were removed and embryos were harvested after removing the jelly coats using $2 \%$ L-cysteine solution. The test solutions were made immediately prior to the exposure experiments.

In the acute test, the serial concentrations of both CAP and ETM were $0.5,0.75,1.0,1.25$ and $1.5 \mathrm{~g} / \mathrm{L}$ and the serial concentrations of TC were $0.01,0.05,0.1,0.25,0.5 \mathrm{~g} / \mathrm{L}$. One FETAX medium, one solvent control (DMSO) and 6 replicates were performed for each treatment group or control. Twenty embryos without jelly coats at stage 10 were put into each 
acid-washed glass Petri dish (90 $\mathrm{mm}$ diameter). The dishes were incubated at $26 \pm 0.5^{\circ} \mathrm{C}$ with $24 \mathrm{~h}$ in dark to avoid the photo-decomposition of test antibiotics. Test solutions were renewed $90 \%$ after removing the dead embryos at $24 \mathrm{~h}$ intervals. After $72 \mathrm{~h}$ of exposure, the surviving embryos were anaesthetized with $100 \mathrm{mg} / \mathrm{L}$ MS-222 immediately, then fixed with $4 \%$ formalin for $24 \mathrm{~h}$, washed with tap water and preserved with $70 \%$ ethanol. In the chronic test, 30 tadpoles at stage 46 (5 dpf) were transferred into each dish (100 mm diameter). The serial concentrations of CAP, ETM and TC were 1, 10, 50 and $100 \mathrm{mg} / \mathrm{L}$. Six replicates were performed for each treatment group. Dead tadpoles were removed and the solutions were renewed at $24 \mathrm{~h}$ intervals. Tadpoles were fed on SERA Micron daily and food levels were adjusted as larvae grew ${ }^{11}$. After $14 \mathrm{~d}$ exposure, the surviving tadpoles were anaesthetized with $100 \mathrm{mg} / \mathrm{L} \mathrm{MS}-222$ and fixed with $4 \%$ formalin.

Observations and measurements of embryos: Embryos were observed with an Olympus SZX16 dissecting microscope (Japan) and images were taken with an Olympus DP 25 camera. The whole body length of embryos or tadpoles was measured from the tip of the head to the tip of the tail using computerassisted image analysis (iSee V3.873). The developmental stages of tadpoles were determined according to Nieuwkop and Faber ${ }^{11}$. The phenotypes of malformation were distinguished and the incidence of each phenotype was evaluated. All the surviving tadpoles in each dish were pooled, dried in an oven at $70{ }^{\circ} \mathrm{C}$ for $48 \mathrm{~h}$ and weighed.

Data analysis: Data were analyzed using SPSS16.0 software. Mean differences among control and treatments were determined by one-way analysis of variance (ANOVA). Each dish was considered a replicate and there were 6 replicates each group $(n=6)$.

\section{RESULTS AND DISCUSSION}

Acute toxicity to the embryos of $X$. tropicalis: No significant differences were observed in the survival rate, the whole body length, biomass, the developmental stages, or teratogenic effects between FETAX medium and DMSO controls. Both the percentage of survival (POS) and the whole body length (WBL) were decreased and the percentage of teratogenesis (POT) was increased in the treatment groups. The POS of CAP was decreased by $1.2-12.7 \%$ and TC was decreased by $26.2 \%$ at $0.25 \mathrm{~g} / \mathrm{L}$, no embryo survival at $0.5 \mathrm{~g} / \mathrm{L}$. But ETM showed no significant effects on survival (Table-1). The whole body length was slightly decreased by 3.4-7.2 \% in CAP treatment groups. For ETM and TC, it was decreased by 2.2-8.9 and 1.3-4.0\%, respectively (Table-1).

After $72 \mathrm{~h}$ of exposure, the embryos showed multiple malformations in three antibiotics treatment groups in different levels (Fig. 1). The percentages of teratogenesis of CAP and TC treatment groups were higher than ETM. The characteristic of malformations were pericardial edema in CAP treatment groups (Fig. 1D). The incidence of this special phenotype was higher than $30 \%$ at $1.5 \mathrm{~g} / \mathrm{L}$ CAP treatment groups (Table-1). Erythromycin showed small eyes, bent tail, skin hypopigmentation and proctodaeum enlarged in phenotype (Fig. 1E$\mathrm{G})$. The percentage of teratogenesis was nearly less than 20 $\%$. In TC treatment groups, the characteristic malformation was wide anal opening (Fig. 1J), the incidence was higher than $60 \%$ at $0.25 \mathrm{~g} / \mathrm{L}$ (Table-1).

Chronic toxicity to the larvas of $X$. tropicalis: The whole body length, biomass and developmental stage were decreased in different levels tests. In CAP treatment groups, the whole body length was decreased by $10.6 \%$ at $100 \mathrm{mg} / \mathrm{L}$, ETM and TC was decreased by 15.7-19.2 and 8-22.8\%, respectively (Fig. 2A-C). The biomass was reduced by $16.9-33.2 \%$ in CAP treatment groups, ETM was reduced by 10.7-15.4\% and TC have significantly decreased by $17.8-67.1 \%$ (Fig. 2D-F). About 1-2 developmental stages were retarded in CAP treatment groups and 1 stage was delayed in both ETM and TC tests (Fig. 2G-I).

TABLE-1

EFFECTS OF CHLORAMPHENICOL (CAP), ERYTHROMYCIN (ETM) AND TETRACYCLINE (TC) ON EMBRYOS (X. tropicalis)

\begin{tabular}{|c|c|c|c|c|}
\hline Range (g/L) & POS $(\%)$ & WBL $(\mathrm{mm})$ & POT (\%) & Special phenotype (\%) \\
\hline Chloramphenicol & - & - & - & Pericardial Edema \\
\hline 0 & $98.6 \pm 2.8 \mathrm{a}$ & $4.40 \pm 0.08$ & $5.4 \pm 4.6$ & $0 \pm 0$ \\
\hline 0.5 & $97.4 \pm 3.0$ & $4.25 \pm 0.03^{*}$ & $18.8 \pm 7.1^{*}$ & $5.3 \pm 4.3$ \\
\hline 0.75 & $97.4 \pm 3.0$ & $4.18 \pm 0.06^{* *}$ & $19.2 \pm 2.9 * *$ & $6.9 \pm 5.4^{*}$ \\
\hline 1.0 & $96.1 \pm 2.6$ & $4.18 \pm 0.05^{* *}$ & $32.4 \pm 6.9 * *$ & $10.7 \pm 5.0^{*}$ \\
\hline 1.25 & $93.3 \pm 2.6 * b$ & $4.16 \pm 0.09 * *$ & $32.6 \pm 6.9^{* *}$ & $14.1 \pm 4.7 * *$ \\
\hline 1.5 & $85.9 \pm 7.8^{*}$ & $4.08 \pm 0.06^{* * *}$ & $43.6 \pm 11.3 * *$ & $34.1 \pm 9.8^{* * *}$ \\
\hline Erythromycin & - & - & - & Proctodaeum Enlarged \\
\hline 0 & $100 \pm 0$ & $4.91 \pm 0.08$ & $9.8 \pm 0.3$ & $8.1 \pm 3.1$ \\
\hline 0.5 & $98.6 \pm 2.8$ & $4.81 \pm 0.11$ & $15.0 \pm 2.2$ & $8.4 \pm 3.6$ \\
\hline 0.75 & $98.7 \pm 2.6$ & $4.80 \pm 0.13^{*}$ & $15.9 \pm 4.5^{*}$ & $10.6 \pm 4.7$ \\
\hline 1.0 & $98.7 \pm 2.6$ & $4.67 \pm 0.15^{* *}$ & $20.0 \pm 2.9 * *$ & $18.6 \pm 2.8^{* *}$ \\
\hline 1.25 & $97.4 \pm 3.0$ & $4.51 \pm 0.09 * *$ & $19.8 \pm 3.3^{* *}$ & $18.5 \pm 3.7 * *$ \\
\hline 1.5 & $97.4 \pm 3.0$ & $4.47 \pm 0.11 * * *$ & $23.0 \pm 2.3 * * *$ & $20.3 \pm 2.5^{* *}$ \\
\hline Tetracycline & - & - & - & Wide Anal Opening \\
\hline 0 & $98.5 \pm 3.0$ & $5.21 \pm 0.04$ & $7.9 \pm 3.0$ & $2.6 \pm 3.0$ \\
\hline 0.01 & $98.6 \pm 2.8$ & $5.22 \pm 0.02$ & $16.7 \pm 7.1$ & $5.4 \pm 6.3$ \\
\hline 0.05 & $98.5 \pm 2.9$ & $5.17 \pm 0.04$ & $17.6 \pm 5.2 *$ & $12.4 \pm 5.5$ \\
\hline 0.1 & $97.3 \pm 3.1$ & $5.14 \pm 0.06$ & $41.8 \pm 8.6^{* * *}$ & $28.4 \pm 14.4 * *$ \\
\hline 0.25 & $73.8 \pm 10.0 * *$ & $5.00 \pm 0.07 * *$ & $75.4 \pm 5.7 * * *$ & $59.0 \pm 13.4^{* *}$ \\
\hline 0.5 & $0 \pm 0 * * *$ & nd & nd & nd \\
\hline
\end{tabular}

Each value represents the mean \pm SD of six replicates; One-way ANOVA was used with $* p<0.05, * * p<0.01$ and $* * * p<0.001$. 


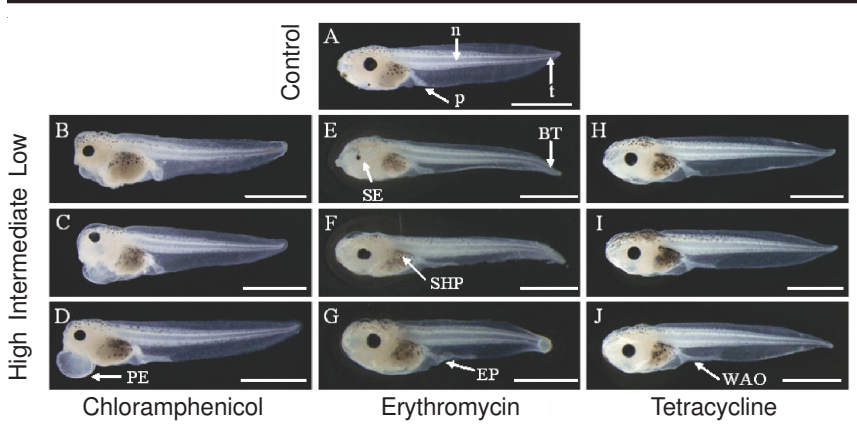

Fig. 1. Teratogenic effects of antibiotics on X. tropicalis embryos after 72 $\mathrm{h}$ of exposure. BT: bent tail; EP: enlarged proctodaeum; $\mathrm{n}$ : notochord; p: proctodaeum; PE: pericardial edema; SHP:skin hypopigmentation; t: tail; WAO:wide anal opening; scale bar: 1 $\mathrm{mm}$

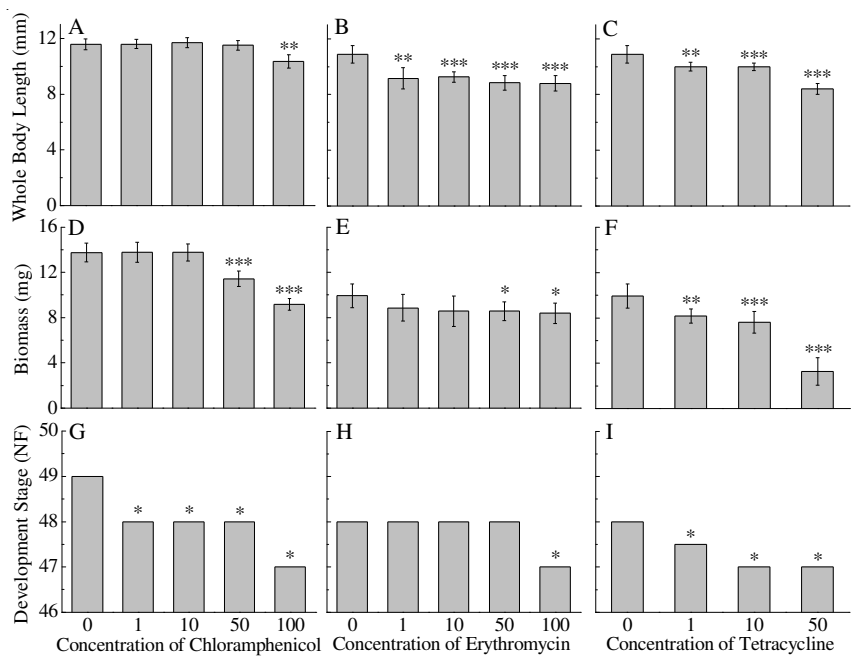

Fig. 2. Effects of chloramphenicol erythromycin and tetracycline on the whole body length, biomass and developmental stage of larvae of $X$. tropicalis after $14 \mathrm{~d}$ of exposure

The occurrence of pharmaceutically active substances was considered a major emerging issue recently. However, the ecotoxicological effects of these chemicals have not yet been adequately revealed. In this study, TC appeared to have a more marked effect than CAP and ETM. Our results also suggest that the chronic test with larvae of $X$. tropicalis were much more sensitive than the acute test with embryos following exposure. CAP has no significant effects to $X$. tropicalis on survival, even in the chronic test. The percentage of survival of $1500 \mathrm{mg} / \mathrm{L}$ chloramphenicol after $72 \mathrm{~h}$ exposure was only decreased by $12.7 \%$, the percentage of $14 \mathrm{~d}$ cumulative mortality was decreased less than $21.7 \%$. Similar findings had demonstrated that when $O$. latipes is exposed to chloramphenicol after $96 \mathrm{~h}$, the $\mathrm{LC}_{50}$ is larger than $1000 \mathrm{mg} / \mathrm{L}$, while M. macrocopa is more sensitive to this chemical, of which the $\mathrm{EC}_{50}$ was only $273.3 \mathrm{mg} / \mathrm{L}^{8}$.

For ETM, it has low toxic to some aquatic organisms, such as T. platyurus and $O$. latipes, with the $\mathrm{LC}_{50}$ above 100 $\mathrm{mg} / \mathrm{L}$ after $24 \mathrm{~h}$ and $96 \mathrm{~h}$ of exposure ${ }^{12}$. Isidori et al. ${ }^{13}$ found that it was more toxic to B. calyctflorus, after $24 \mathrm{~h}$ of exposure, the $\mathrm{LC}_{50}$ was $27.5 \mathrm{mg} / \mathrm{L}$ and the chronic test $(7 \mathrm{~d}) \mathrm{LC}_{50}$ was equal to $0.94 \mathrm{mg} / \mathrm{L}$. In this study, the cumulative mortality was $33.3 \%$ at $100 \mathrm{mg} / \mathrm{L}$ in the chronic test, no significant effects were observed in the acute test. Tetracycline is more toxic than the other two chemicals. Wollenberger et al. ${ }^{14}$ investigated that it was no effects of tetracycline on D. magna after $48 \mathrm{~h}$ exposure at $340 \mathrm{mg} / \mathrm{L}$, but after $21 \mathrm{~d}$ exposure $\mathrm{EC}_{50}$ was only $44.8 \mathrm{mg} / \mathrm{L}$. In our chronic test, the cumulative mortality of $X$. tropicalis larvaes was approaching $50 \%$ at 50 $\mathrm{mg} / \mathrm{L}$.

\section{Conclusion}

The study indicated three antibiotics have teratogenic effects on the embryos of $X$. tropicalis at a high concentration. The characteristics of malformations include pericardial edema, enlarged proctodaeum and wide anal opening. The order of toxicity was TC $>$ CAP $>$ ETM. In the chronic toxicity test, antibiotics have lethal effects on the larvaes of $X$. tropicalis at a low concentration and the $\mathrm{LC}_{50}$ values were found in the range of 36-290 $\mathrm{mg} / \mathrm{L}$. These results suggested these antibiotics could exert adverse effects on higher trophic level organism even humans by food chains as well as on amphibians in environment.

\section{ACKNOWLEDGEMENTS}

This study was supported by Innovation Program of Shanghai Municipal Education Commission (12YZ128).

\section{REFERENCES}

1. A.K. Sarmah, M.T. Meyer and A.B.A. Boxall, Chemosphere, 65, 725 (2006).

2. R. Wise, J. Antimicrob. Chemother, 49, 585 (2002).

3. M.S. Nawaz, B.D. Erickson, A.A. Khan, S.A. Khan, J.V. Pothuluri, F. Rafii, J.B. Sutherland, R.D. Wagner and C.E. Cerniglia, Regul. Res. Perspect., 1, 1 (2001).

4. A. Al-Ahmad, F.D. Daschner and K. Kümmerer, Arch. Environ. Contam. Toxicol., 37, 158 (1999).

5. S. Handerson, R.A. Brain, D.J. Johnson, C.J. Wilson and K.R. Solomon, Toxicology, 203, 27 (2004).

6. H.T. Lai, J.H. Hou, C.I. Su and C.L. Chen, Ecotoxicol. Environ. Saf., 72, 329 (2009).

7. M. De Liguoro, B. Fioretto, C. Poltronieri and G. Gallina, Chemosphere, 75, 1519 (2009).

8. K. Choi, Y. Kim, J. Jung, M.H. Kim, C.S. Kim, N.H. Kim and J. Park, Environ. Toxicol. Chem., 27, 711 (2008).

9. L. Yu, X. Zhang, J. Yuan, Q. Cao, J. Liu, P. Zhu and H. Shi, J. Hazard. Mater., 192, 1860 (2011).

10. Annual Book of ASTM Standards, ASTM, Philadelphia, PA, Vol. 11.05 p. 826 (1998).

11. P.D. Nieuwkop and J. Faber, Normal Table of Xenopus laevis (Daudin). New York: Garland Science Publishing (1992).

12. J.W. Kim, H. Ishibashi, R. Yamauchi, I.N. Chikawa, Y. Takao, M. Hirano and K. Arizono, J. Toxicol. Sci., 34, 227 (2009).

13. M. Isidori, M. Lavorgna, A. Nardelli, L. Pascarella and A. Parrella, Sci. Total Environ., 346, 87 (2005).

14. L. Wollenberger, B. Halling-Sørensen and K.O. Kusk, Chemosphere, 40, 723 (2000). 